\title{
HISTÓRIA E LIBERDADE: A ESPERANÇA DE FREIRE E DE SPINOZA
}

\section{Juliana Merçon*}

\begin{abstract}
RESUMO
A noção de esperança ocupa uma posição central na obra de Paulo Freire. Por compreendê-la como motora da mudança, necessidade ontológica e ato político, Freire conclui que é preciso educar a esperança para que não se converta em desesperança infértil ou desespero trágico. Em espírito freireano, meu propósito neste artigo é o de tecer um diálogo entre o pensamento deste grande educador e a filosofia de Spinoza. Este encontro impossível entre esses dois homens que se rebelaram, em pensamento e ato, contra as opressões de seus tempos, transcorrerá por meio da investigação dos seguintes temas: 1) o papel da esperança na noção freireana de história; 2) as relações entre liberdade e necessidade; 3) as funções sociais da esperança e 4) a proposta de 'educação da esperança'. Duas noções de esperança serão discutidas: a esperança ingênua e a esperança crítica. A provocação spinozana consistirá em sugerir uma postura ética e política que, movida por nossa potência para pensar e agir, prescinde da esperança.
\end{abstract}

Palavras-chave: Freire. Spinoza. Esperança. Liberdade. Necessidade.

\begin{abstract}
The notion of hope occupies a central position in Paulo Freire's work. Since he understands hope to be a motor for change, an ontological necessity and a political act, Freire concludes that it is important to educate hope so that it is not converted into infertile hopelessness or tragic despair. Imbued with Freirean spirit, my purpose in this paper is to construct a dialogue between this great educator's thoughts and those of
\end{abstract}

Doutorado em Educação pela Universidade Estadual do Rio de Janeiro (UERJ). Doutoranda em Filosofia na University of Queensland Brisbane (UB, Austrália). Professora titular de Educação para a Sustentabilidade do Instituto de Investigaciones em Educación da Universidade Veracruzana (Xalapa, México).E-mail: julianamercon@gmail.com 
Spinoza. This impossible encounter between these two men who rebelled in thought and action against the oppressions of their times will occur through the investigation of the following themes: 1) the role of hope in the Freirean conception of history; 2) relationships between freedom and necessity; 3) hope's social functions and 4) Freire's proposal of an 'education of hope'. Two notions of hope will be discussed: naïve hope and critical hope. The spinozist provocation consists in suggesting an ethical and political attitude which is primarily moved by our power to think and act and is, therefore, not based on hope.

Keywords: Freire. Spinoza. Hope. Freedom. Necessity.

\section{Esperança e história}

Seria uma contradição se, inacabado e consciente do inacabamento, primeiro, o ser humano não se achasse predisposto a participar de um movimento constante de busca e, segundo, se buscasse sem esperança (FREIRE, 2000, p. 80).

A incompletude é, para Freire e para toda uma longa tradição filosófica, uma marca indissolúvel do humano. A consciência de nossa incompletude nos colocaria em um movimento de busca incessante, uma busca guiada por nossas esperanças. A ação humana encontraria, assim, na consciência de que muito nos falta a sua causa eficiente e na esperança de preencher este vazio o espelho de um desejo movido por causas finais. Entre a falta e o querer transcorreria a ação humana, tingida por suas lacunas e por suas esperanças.

A esperança assevera Freire, é uma necessidade ontológica: não é algo que se justaponha à natureza humana, mas que a constitui e define. Já a desesperança "é esperança que, perdendo sua direção, se converte em distorção da necessidade ontológica" (FREIRE, 1993, p. 8). A desesperança nos paraliza e nos faz sucumbir ao fatalismo, posição na qual se torna impossível reunir as forças indispensáveis para recriar o mundo. A tarefa de recriação do mundo faria da esperança um "ato político necessário".

Necessidade ontológica e ato político. Assim definida, a noção de esperança permite a Freire afirmar uma certa concepção de História. 
A importância atribuída a este desejar esperançoso em sua relação com o fazer histórico pode ser lida nas entrelinhas de várias narrativas presentes na obra do educador pernambucano. Insatisfeito e desafiado pela miséria e opressão que encontra no mundo, Freire sabe que há muito o que transformar. No longo fragmento que segue, o educador nos fornece uma imagem de sua inconformidade:

Caminhávamos, um jovem educador popular chamado Danilson e eu, com alma aberta ao mundo, curiosos, receptivos, pelas trilhas de uma favela onde cedo se aprende que só a custo de muita teimosia se consegue tecer a vida com sua quase ausência - ou negação -, com carência, com ameaça, com desespero, com ofensa e dor. Enquanto andávamos pelas ruas daquele mundo maltratado e ofendido eu ia me lembrando de experiências de minha juventude em outras favelas de Olinda ou do Recife, dos meus diálogos com favelados e faveladas de alma rasgada. Tropeçando na dor humana, nós nos perguntávamos em torno de um sem número de problemas. Que fazer, enquanto educadores, trabalhando num contexto assim? (...) Paramos no meio de um pontilhão estreito. Olhávamos de cima um rio poluído, sem vida, cuja lama, e não água, empapava os barracões ou mocambos nela quase mergulhados. "Mais além dos mocambos", me disse Danilson, "há algo pior: um grande terreno onde se faz o depósito do lixo público. Os moradores de toda esta redondeza buscam no lixo o que comer, o que vestir, o que os mantenha vivos". Foi deste horrendo aterro, que há dois anos, uma família retirou de um lixo hospitalar pedaços de seio amputado com que preparou seu almoço de domingo. A imprensa noticiou o fato. (...) É possível que a notícia tenha provocado em pragmáticos neoliberais sua reação habitual e fatalista sempre em favor dos poderosos. "É triste, mas, que fazer? A realidade é mesmo esta." A realidade, porém, não é inexoravelmente esta. Eu me sentiria mais do que triste, desolado e sem achar sentido para minha presença no mundo, se fortes e indestrutíveis razões me convencessem de que a existência humana se dá no domínio da determinação. Domínio em que dificilmente se poderia falar de opções, de decisão, de liberdade, de ética (FREIRE, 1993, p. 82-83). 
Freire parece afirmar que diante das mazelas sociais que afligem o espírito crítico haveria apenas dois posicionamentos. De um mesmo lado, estariam os fatalistas, sejam eles "reacionários" ou "pragmáticos neoliberais", para quem o futuro é uma acomodação a fatos e verdades imutáveis, sempre reproduzidas, assim como estariam também supostos "revolucionários" para quem o futuro ocorrerá como progresso inexorável. Em contraposição a estas visões fatalistas de direita e de esquerda, Freire defende uma compreensão da história como possibilidade. Nesta visão da história como futuro aberto e em permanente construção, a esperança atua como motor. Sem esperança, nos diz Freire, não haveria História, mas sua "desproblematização" ou puro determinismo. Nas palavras do autor:

A desproblematização do futuro numa compreensão mecanicista da História, de direita ou de esquerda, leva necessariamente à morte ou à negação autoritária do sonho, da utopia, da esperança. É que, na inteligência mecanicista portanto determinista da História, o futuro é já sabido. A luta por um futuro assim "a priori” prescinde da esperança. A desproblematização do futuro, não importa em nome de quê, é uma violenta ruptura com a natureza humana social e historicamente constituindo-se (FREIRE, 1993, p. 82).

Talvez seja verdade que o determinismo prescinda da esperança. Mas seriam as concepções de história apresentadas por Freire as únicas possíveis? Não poderiam haver outras ideias e posturas que não se aliam a fatalismos que concebem o futuro como já sabido nem a aberturas que negam determinismos? E seria mesmo tão absurdo falar de liberdade e ética no domínio da determinação ou da necessidade?

\section{Liberdade e necessidade?}

Não podemos dizer que um homem é livre porque pode deixar de pensar ou porque possa preferir um mal a um bem (...).

Aquele que existe e age por uma necessidade de sua própria natureza, age livremente (...).

A liberdade não tira a necessidade de agir, mas a põe. (SPINOZA, TP II) 
Um conjunto de distinções que pretendem separar liberdade e necessidade foi estabelecido pela tradição teológico-metafísica ocidental. Chauí (2002, p. 9-10) mostra como estas diferenciações ainda hoje utilizadas para compreender o funcionamento de entes e eventos possuem sua origem no pensamento teológico. Dizia-se, por exemplo, que é "por natureza" o que acontece "por necessidade" e, ao contrário, que é "por vontade" o que acontece "por liberdade". A operação necessária era atribuída à causa eficiente enquanto a ação livre cabia à articulação entre a causa formal (ou seja, a essência do agente) e a causa final (o télos da ação), de maneira que a liberdade se efetuava com relação a fins. Identificando o natural e o necessário, de um lado, e o voluntário e o livre, de outro, essa tradição afirmou que Deus, sendo onipotente e onisciente, não poderia agir por necessidade, mas apenas por liberdade e, portanto, somente por vontade. Da mesma maneira, tendo sido criados à imagem e semelhança de Deus, os humanos eram concebidos como agentes livres, isto é, dotados de vontade livre. A necessidade natural era explicada como operação da causa eficiente enquanto a liberdade divina e humana era explicada como operação da causa final. Como agir em vista de fins pressupõe inteligência ou razão, a ação voluntária era considerada ação inteligente enquanto a operação natural ou necessária era considerada automatismo cego e bruto.

A aclamada secularização do pensamento não foi capaz de desfazer a crença de que somos fonte de livre vontade, embora alguns filósofos tenham oferecido consistentes alternativas. Este é o caso de Spinoza, que já no século XVII tece explicações para esta persistente ideia de que a vontade humana é livre. Diz o filósofo que é por ignorarmos as causas de nosso desejo, por desconhecermos os caminhos pelos quais somos levados a pensar e agir de certas maneiras, que cremos que somos regidos por nossa razão e pelas causas finais que supostamente elegemos livremente (E4 Pref.). ${ }^{1}$ A naturalização da experiência humana, e particularmente da ética, estão na base do projeto spinozista.

1 A referência à Ética de Spinoza conterá indicação da parte do livro com algarismo arábico, seguida de P para proposição; D demonstração; Cor. corolário; Def. Af. definição dos afetos; Post. postulado; Pref. prefácio; Esc. escólio. Fonte utilizada: Tradução de Tomaz Tadeu. Belo Horizonte: Autêntica, 1677/2007. 
Spinoza descreve um universo onde para tudo o que existe há uma causa necessária e tudo o que não possui uma causa determinada não existe. Chamamos possível, explica o filósofo, àquilo que vemos acontecer ou imaginamos que acontecerá, mas cujas causas verdadeiras e necessárias de sua produção desconhecemos. Em suma, o possível é, para Spinoza, reflexo de nossa ignorância quanto à causa de alguma coisa - ignorância que nos constitui como seres sempre finitos.

Por sermos modificações finitas do todo que é a natureza, por sermos partes dotadas de uma certa potência mas sempre extrinsicamente determinadas, nunca compreenderemos completamente a totalidade complexa, física e social, que integramos. O desconhecimento sempre nos acompanhará, embora o experienciemos em doses distintas. Desta nossa ignorância constitutiva nasce a crença de que nosso desejo e ação não são determinados e, subsequentemente, a atraente ilusão de que somos livres. Esta liberdade ilusória não passaria, porém, de uma mostra de nossa ignorância.

Apesar de denunciar a forte ilusão associada à vontade livre e afirmar um mundo marcado pelo determinismo, Spinoza não rejeita a noção de liberdade, mas a reconceitualiza. Segundo o filósofo, a liberdade não é a indeterminação que precede uma escolha contingente nem é a indeterminação dessa escolha. A liberdade não é escolha voluntária nem ausência de causa ou uma ação sem causa. O que seria então a liberdade para Spinoza?

O filósofo holandês é conhecido por associar o que para muitos é logicamente incompatível. Necessidade e liberdade não são ideias opostas, mas concordantes no sistema spinozista. Isto porque a liberdade não é negação da necessidade, mas a sua afirmação pela potência do nosso pensamento: quanto mais compreendemos de que maneiras somos determinados, mais seremos livres para agir. Esta ação não negaria, portanto, sua própria determinação, mas justamente por conhecer como é determinada será capaz de atuar mais efetivamente. Inversamente, o não entendimento das causas que nos determinam nos mantêm presas em situações adversas, oscilando entre impotências geradas ora pela crença em nossa vontade livre, ora pelo poder ilusório de agentes externos que percebemos como fontes exclusivas de nosso desprazer ou sofrimento. 
Assim como a liberdade depende de nossa potência de pensar e compreender a causalidade complexa que nos faz querer e agir de certas maneiras e não de outras, a ética também se radica na afirmação e ampliação do pensamento. Nossa potência para pensar e agir é sempre atual ou manifesta, segundo a ordem causal na qual se insere: a cada instante expressamos o que podemos naquele instante. Temos, portanto, uma certa noção daquilo que podemos. Não compreendemos, porém, como exatamente somos determinados e, principalmente, como o seremos nos instantes futuros. Consequentemente, não conhecemos completamente quais são os limites de nossa potência, nunca sabemos exatamente de que seremos capazes. Nossa ignorância constituinte nos faz perceber a história como um terreno marcado pela possibilidade e o transforma em um espaço aberto para a experimentação de nossas potências individuais e coletivas. Não sabendo precisamente como somos afetados na complexa rede que é o mundo e não sabendo precisamente de que somos capazes, podemos apostar em nossas forças e assim empenhar-nos para que nossos corpos e mentes tendam à sua máxima atividade. A impossibilidade de um saber completo sobre como somos determinados e como nossas ações determinam outros eventos nos faz crer em um futuro como possibilidade. Poderíamos assim dizer que a concepção spinozista de história que deriva da perspectiva sempre limitada dos humanos se aproxima da noção de 'história como possibilidade' defendida por Freire. Não obstante, como mostramos, esta aproximação ocorre por razões bastante distintas.

\section{Uma ética sem esperança?}

Os afetos da esperança e do medo não existem sem a tristeza (SPINOZA, E4 P47 D).

Vimos que a partir de sua concepção de história como abertura ou possibilidade, Freire atribui à esperança um papel fundamental. Diz ser a esperança uma necessidade ontológica, uma espécie de motor da mudança e, portanto, um ato político positivo. Já para Spinoza, veremos que a esperança não pode ser, por ela mesma, algo bom, pois é um afeto 
que indica, antes de mais nada, uma carência de conhecimento e uma impotência do pensamento (E4 P47 e Esc.).

A alegria é definida por Spinoza como um afeto pelo qual nossa potência é aumentada. A tristeza, inversamente, é um afeto que indica a diminuição de nossa potência de pensar e agir (E3 Def. Af. 3 Exp. ). A esperança é uma alegria instável surgida da ideia de uma coisa futura ou passada, de cuja realização temos alguma dúvida (E3 Def. Af. 12). Segundo Spinoza, o afeto de esperança está sempre acompanhado de seu oposto: o medo. Sentir medo é vivenciar uma tristeza instável, surgida da ideia de uma coisa futura ou passada, de cuja realização temos alguma dúvida (E3 Def. Af. 13). Excluída a dúvida, a esperança dá lugar à segurança e o medo ao desespero (E3 P18 Esc. 2). Quando estamos apegados à esperança, e temos dúvida sobre a realização de uma coisa, imaginamos algo que exclui a existência da coisa futura e, portanto, dessa maneira, entristecemo-nos. Como consequência, enquanto estamos apegados à esperança, temos medo de que a coisa não se realize (E3 Def. Af. 13 Exp. ). Esperança e medo não existem sem a tristeza, isto é, são sempre sinais da diminuição de nossa potência de compreender e agir.

Por sermos partes e não o todo que é a natureza, por sermos finitos e extrinsicamente determinados, por nossos corpos registrarem os efeitos de outros corpos, mas nem sempre o intelecto ser capaz de pensar suas causas, nossa ignorância faz-nos seres desejantes do que não é e, em muitos casos, do que não pode ser. A esperança, esse querer voltado ao futuro e alimentado por nossos dessaberes, talvez seja, de fato, como afirma Freire, uma de nossas marcas ontológicas.

Como ato político, no entanto, Spinoza nos diria que a esperança não desempenha, necessariamente, uma função positiva. A esperança nem sempre move a mudança e pode inclusive dificultar que conheçamos adequadamente as verdadeiras causas eficientes de nosso desejar esperançoso. Quanto mais compreendemos as redes causais em que os acontecimentos se tecem, mais podemos agir efetivamente no presente, contribuindo para a instauração de transformações que estão conformes ao nosso entendimento. Esperar que a mudança ocorra de uma certa maneira e não de outras, de acordo com a nossa vontade ou esperança, significa nutrir um desejo desconectado da complexidade causal própria e de seu objeto. 
Não são os fins que explicam os estados presentes, mas as configurações atuais, movidas ou não pela imaginação de que aquilo a que se dirige nosso querer causa nossa ação.

Spinoza sugere que a esperança e o medo estão na base da sociabilidade humana. Porque somos conduzidos por afetos passivos, cujas determinações desconhecemos, mais do que por afetos ativos que expressam a potência do nosso pensamento, não é em virtude da força do nosso entendimento que nos unimos como sociedade, mas principalmente por compartimos nossa ignorância, expressa em afetos como a esperança e o medo (TP VI 1). É por termos a esperança de vivenciar um bem maior e o medo de sermos afligidos por um mal maior que nos unimos sob as regras da sociedade civil. Nossa ignorância constitutiva gera discórdias e injustiças, mas também, como vemos agora, nos permite criar laços sociais dos quais a vida humana se beneficia.

A vida em sociedade, fundada sobre nossa passividade e ignorância, sempre envolve os afetos de esperança e medo. A intensidade com a qual estes afetos se manifestam é um indicativo da própria potência do Estado. Assim como a vida de uma pessoa se mostra frágil e ameaçada quando os afetos de esperança e medo predominam, a vida coletiva que é dominada por estes afetos manifesta instabilidades que podem vir a ser destrutivas (TP III 9). Segue que um Estado potente, sábio e virtuoso é aquele no qual seus membros poucos motivos possuem para temer, assim como menos se projetam no sonho de alegrias futuras por meio da esperança.

\section{Educação da esperança}

Sem um mínimo de esperança não podemos nem sequer começar o embate, mas sem o embate a esperança, como necessidade ontológica, se desordena e se converte em desesperança que às vezes se alarga em trágico desespero.

Dai que seja necessário educar a esperança.

(FREIRE, 1993, p. 8). 
Freire propõe que para evitar que a esperança seja convertida em desesperança ou, mais gravemente, em desespero, seria importante 'educar a esperança'. A desesperança não expressa, segundo Freire, a natureza humana. Razões distintas podem levar-nos a situações de desesperança, por meio das quais nos distanciamos de nosso próprio ser. Esta realidade implica consequências éticas e políticas, como a luta por diminuir as causas, objetivas e subjetivas, da desesperança imobilizante. Neste sentido, a tarefa educativa teria tanto um aspecto negativo no sentido de impedir ou dificultar a manifestação da desesperança ou desespero, assim como um aspecto positivo ao fazer surgirem formas de compreensão da realidade que revigorariam o desejar esperançoso.

"Não há mudança sem sonho, assim como não há sonho sem esperança", nos diz Freire (1993, p. 87). Uma impressão que pode nos chegar com esta afirmação é a de que Freire crê em um sujeito capaz de modificar o mundo por ser movido por seu simples desejo. A esperança aqui vista como motora do sonho que torna possível toda a mudança abriga consideráveis perigos voluntaristas. O educador, porém, não é assim tão ingênuo. Freire esclarece:

Isto não quer dizer, no entanto, que porque sou esperançado atribua à minha esperança o poder de transformar a realidade, e convencido disso me lance ao embate sem tomar em consideração os dados concretos, materiais, afirmando que minha esperança basta. Minha esperança é necessária mas não é suficiente. Ela sozinha não ganha a luta, mas sem ela a luta enfraquece e titubea. Necessitamos a esperança crítica como o peixe necessita da água incontaminada (FREIRE, 1993, p. 8, grifo meu).

Freire esclarece que a esperança sozinha não é capaz de transformar o mundo e que agir movido por essa ingenuidade é uma forma de deixarse levar a um estado de desesperança, pessimismo ou fatalismo. Por outro lado, "prescindir da esperança na luta por melhorar o mundo, como se a luta pudesse se reduzir exclusivamente a atos calculados, à pura cientificidade, é frívola ilusão" (FREIRE, 1993, p. 8). Para Freire, a esperança se funda não apenas na verdade como também na qualidade ética da luta - negá- 
la equivale, portanto, a desconsiderar um dos suportes fundamentais da própria mudança. Para que seja crítica, a esperança necessita ancorar-se na prática, como necessidade ontológica, a esperança necessita da prática para tornar-se história concreta. Por esta razão, conclui Freire, "não há esperança na pura espera" (FREIRE, 1993, p. 8, grifo meu).

A esperança crítica não se fundamenta em um sujeito isolado com sua vontade ingênua. Não corresponde a uma 'pura espera', infértil, senão a um sonhar ativo que transforma o pensamento crítico em ação. Talvez seja verdade que nossa frágil natureza humana seja constituída por muitas esperas e esperanças. Talvez não nos seja possível viver sem, em momento algum querer o que não é sem ter expectativas ou de alguma maneira nos empenhar para realizar o que nosso desejo imagina para o futuro. É verdade que entre esperanças ingênuas e esperanças críticas, o melhor seria cultivar as segundas, isto é, compreender nossos sonhos como uma parte de um todo complexo, como um querer que não somente atua como condição para a mudança senão que reconhece ser também condicionado por nosso entorno.

Com premissas e argumentos distintos, Spinoza concordaria com esta conclusão. Diria-nos que diante da impossibilidade de uma compreensão global e efetiva da realidade, a esperança e o medo trazem mais vantagens à vida comum que desvantagens. Se as pessoas não temessem males maiores ou não tivessem a esperança de uma vida melhor, elas não se uniriam em sociedade e assim encontrariam ainda mais obstáculos para a afirmação de suas próprias potências (E4 P54 Esc.). Apesar de envolver tristezas, ignorâncias ou impotências, a esperança cumpre uma importante função social.

Se a espera ingênua reflete uma profunda passividade ou impotência para pensar e agir, a esperança crítica da qual nos fala Freire seria para Spinoza uma espécie de mal menor. Menor porque possui efeitos de coesão social e porque pode, inclusive, auxiliar-nos a compreender os dados concretos das situações a serem modificadas. Não obstante, nascida de nossa impotência para entender por que as coisas são como são, a esperança seguiria sendo para Spinoza um afeto associado ao medo e à tristeza. Quanto mais nos esforçamos por viver sob a condução de uma compreensão efetiva e potente, tanto mais nos esforçamos por nos 
livrar do medo e por depender menos da esperança (E4 P54 Esc.). Neste sentido, Spinoza nos inspira a outras maneiras de habitar o presente em suas dimensões éticas e políticas, assim como a uma outra 'educação da esperança'.

Em clave spinozista, penso que a educação do desejar esperançoso passaria justamente pela desintensificação deste afeto. Este processo ocorreria por meio da afirmação de desejos mais ativos, expressos como compreensão complexa das relações sociais e como ação efetiva, instauradora de presentes mais justos e sábios, aqui e agora. A educação do presente mediante a coletivização da potência de pensar e de atuar cada vez mais justa e admiravelmente não estaria centrada no desejo de um certo futuro (não sendo, portanto, movida por supostas causas finais), mas no entendimento complexo e na ação comunitária que nos fazem menos atrelados a esperanças, mais atentos às condições atuais e mais realizadores do mundo que queremos.

É certo que Freire não se oporia à ideia de que é necessário conduzir uma transformação imediata dos processos que constituem nossa realidade ou viver a pronta construção do mundo que desejamos. Como vimos anteriormente, uma diferença crucial entre os autores residiria no papel destinado à esperança como condição necessária para a realização de mudanças sociais. Se para Freire a educação da esperança implica o cuidado para que esta última não deixe de existir e passe a ser cada vez mais crítica, desde uma perspectiva spinozista, educar a esperança talvez signifique enfraquecê-la por meio do fomento ao entendimento e à ação efetivos, visto que este aumento em nossa potência de pensar e agir nos tornaria menos dependentes ou desejosos de situações duvidosas.

Apesar deste e de outros desencontros teóricos, a vida e a obra tanto de Freire como de Spinoza atestam diversas forças comuns. A potência de seus pensamentos, sua inconformidade crítica frente às injustiças e à escravização das mentes, assim como a inspiração sempre atual de seus legados nos convidam a não esperar senão que a pensar complexamente e a atuar para a construção de um mundo melhor. 


\section{Referências}

CHAUÍ, Marilena. Poder e liberdade: a política em Espinosa. Cadernos de Ética e Filosofia Política, São Paulo, n. 4, 2002.

FREIRE, Paulo. Pedagogía de la esperanza. México: Siglo Veintiuno, 1993.

. Pedagogia da autonomia. Saberes necessários à prática educativa. São Paulo: Paz e Terra, 2000.

SPINOZA, Benedictus de. Tratado Político. Coleção Os Pensadores. Tradução de Manuel de Castro. São Paulo: Abril Cultural, 1677/1997.

. Ética. Tradução de Tomaz Tadeu. Belo Horizonte: Autêntica, 1677/2007.

Data de registro: $21 / 07 / 2011$

Data de aceite: 19/10/2011 
